\title{
Lacrimal gland enlargement in acute myeloid leukemia
}

Sir,

An 18-year-old male got admitted to emergency room (ER) of our hospital, a tertiary care center, for evaluation of bilateral protrusion of eyeballs. There was history of easy fatigability and ill-health for past 2 months. His clinical 


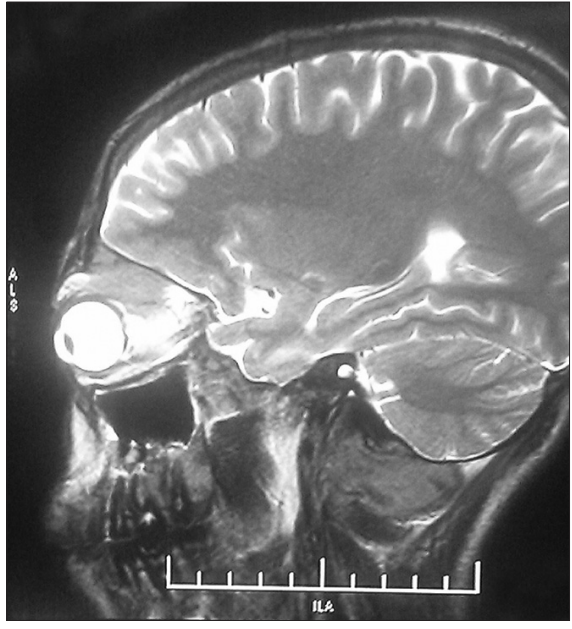

Figure 1: Eye balls pushed in CT orbit

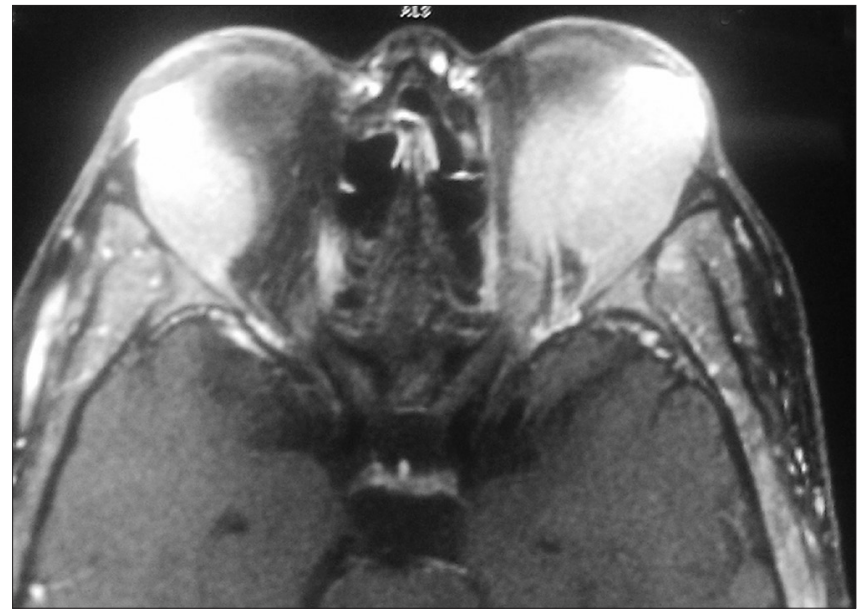

Figure 3: Enlarged lacrimals pushing eyeballs

examination revealed anemia and bilateral proptosis. CBC showed $\mathrm{Hb} 8 \mathrm{~g} / \mathrm{dl}$, TLC 18 k, DLC 80\% myeloblasts, platelets $70 \mathrm{k}$. Computed tomography (CT) scan of the orbits revealed lacrimal gland enlargement pushing eyeballs medially and down [Figures 1-4]. The patient was shifted to medical oncology department on the same day.

The aim of highlighting this image is how varied can be the differential diagnosis in a patient presenting as proptosis.

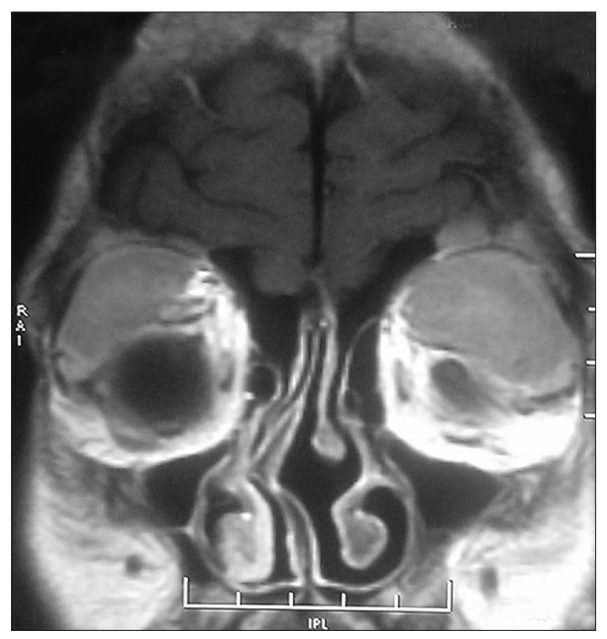

Figure 2: Lacrimal gland enlarged

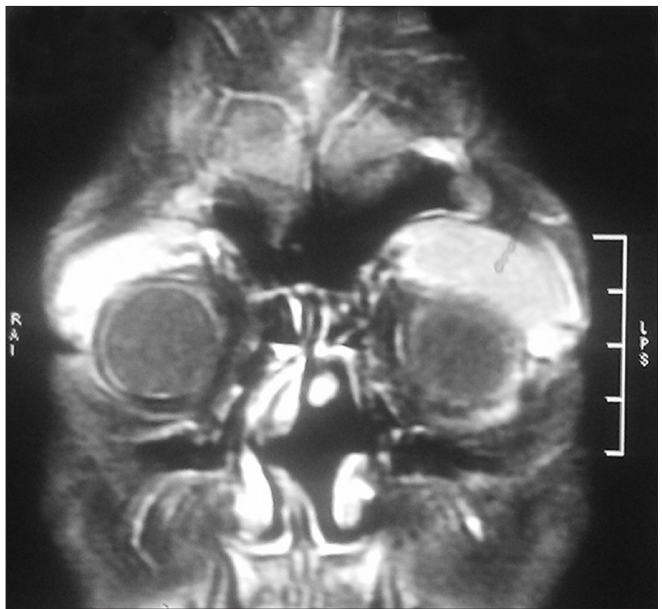

Figure 4: Eyeballs compressed supero laterally

Ajaz N. Koul, Muzaffar M. Khujwal

Department of Medicine, Sher-I-Kashmir Institute of Medical Sciences, Soura, Srinagar, India. E-mail: ajazkoul@yahoo.com

\begin{tabular}{|l|l|}
\hline \multicolumn{2}{|c|}{ Access this article online } \\
\hline Quick Response Code: & Website: \\
\hline & www.ijmpo.org \\
\cline { 2 - 2 } & \\
\hline
\end{tabular}

